This is the author's final, peer-reviewed manuscript as accepted for publication. The publisher-formatted version may be available through the publisher's web site or your institution's library.

\title{
One-step synthesis of graphene via catalyst-free gas-phase hydrocarbon detonation
}

Arjun Nepal, Gajendra P. Singh, Bret N. Flanders and C. M. Sorensen

\section{How to cite this manuscript}

If you make reference to this version of the manuscript, use the following information:

Nepal, A., Singh, G. P., Flanders, B. N., \& Sorensen, C. M. (2013). One-step synthesis of graphene via catalyst-free gas-phase hydrocarbon detonation. Retrieved from http://krex.ksu.edu

\section{Published Version Information}

Citation: Nepal, A., Singh, G. P., Flanders, B. N., \& Sorensen, C. M. (2013). One-step synthesis of graphene via catalyst-free gas-phase hydrocarbon detonation. Nanotechnology, 24(24), 245602.

Copyright: 2013 IOP Publishing Ltd

Digital Object Identifier (DOI): doi:10.1088/0957-4484/24/24/245602

Publisher's Link: http://iopscience.iop.org/0957-4484/24/24/245602/

This item was retrieved from the K-State Research Exchange (K-REx), the institutional repository of Kansas State University. K-REx is available at http://krex.ksu.edu 


\title{
One-step synthesis of graphene via catalyst-free gas-phase hydrocarbon detonation
}

\author{
Arjun Nepal, ${ }^{a}$ Gajendra P. Singh, ${ }^{\mathrm{a}, \mathrm{b}}$ Bret N. Flanders ${ }^{\mathrm{a}}$ and C. M. Sorensen ${ }^{\mathrm{a} *}$ \\ ${ }^{\mathrm{a}}$ Department of Physics, Kansas State University, Manhattan, Kansas-66506, USA \\ ${ }^{\mathrm{b}}$ Centre for Nanotechnology, Central University of Jharkhand, Ranchi-835205, Jharkhand, India,
}

\begin{abstract}
A one-step, gas-phase, catalyst-free detonation of hydrocarbon $\left(\mathrm{C}_{2} \mathrm{H}_{2}\right)$ method was developed to produce gram quantities of pristine graphene nanosheets (GNs). The detonation of $\mathrm{C}_{2} \mathrm{H}_{2}$ was carried out in the presence of $\mathrm{O}_{2}$. The molar ratios of $\mathrm{O}_{2} / \mathrm{C}_{2} \mathrm{H}_{2}$ were $0.4,0.5,0.6,0.7$, and 0.8 . The obtained GNs were analyzed by XRD, TEM, XPS and Raman spectroscopy. The GNs are crystalline with $(002)$ peak centered at $26.05^{\circ}(d=0.341 \mathrm{~nm})$. TEM shows that the GNs are stacked in two to three layers and sometimes single layers. An increase in the size of GNs $(35-250 \mathrm{~nm})$ along with reduction in defects (Raman $\left.\mathrm{I}_{\mathrm{D}} / \mathrm{I}_{\mathrm{G}} \sim 1.33-0.28\right)$ and specific surface area (187 to $23 \mathrm{~m}^{2} \mathrm{~g}^{-1}$ ) was found with increasing $\mathrm{O}_{2}$ content. The high temperature of the detonation, ca. $4000 \mathrm{~K}$, is proposed as the cause of graphene production rather than normal soot. The method allows for the control of the number of layers, shape and size of the graphene nanosheets. The process can be scaled up for industrial production.
\end{abstract}

\section{Introduction}

Graphene is a two dimensional monolayer of $\mathrm{sp}^{2}$ bonded carbon atoms in a hexagonal crystal structure. It has been drawing considerable interest because of its unique physical properties including excellent mechanical strength, high intrinsic carrier mobility at room temperature, and electrical and thermal conductivity comparable to the in-plane value of graphite. ${ }^{1-3}$ These properties open gateways for the potential applications of graphene in technological areas such as nanoelectronics, ${ }^{4,5}$ sensors, ${ }^{6}$ nanocomposites, ${ }^{7,8}$ batteries, ${ }^{9}$ supercapacitors, and hydrogen storage. ${ }^{10}$ Pioneering work for the production of graphene was first done by the micromechanical cleavage of highly ordered pyrolytic graphite (HOPG). ${ }^{10,11}$ 
However, the low yield makes it unsustainable for large scale use. Numerous methods for preparation of graphene nanosheets have since been developed including chemical vapor deposition (CVD), ${ }^{12,13}$ ultrasonication-assisted exfoliation of graphene oxide (GO) from graphite oxide in water, ${ }^{14}$ epitaxial growth on an electrically insulating surface, ${ }^{15}$ solution-based chemical reduction of $\mathrm{GO},{ }^{16}$ rapid thermal exfoliation of expanded graphite into graphene ${ }^{17}$, high temperature heating of polymer on metal/insulator surface, ${ }^{18}$ and gas-phase plasma synthesis ${ }^{19}$. Notably, the CVD method has been used in a roll-to-roll production of 30 -inch monolayer graphene films. $^{20}$

For the production of large quantities of graphene, the modified Hummer's method for the production of GO through chemical exfoliation of graphite to graphite oxide and then graphite oxide to GO has gained much attention due to low-cost and higher yield in comparison to other methods. ${ }^{21-24}$ However, this method is not ideal because the GO produced suffers from some important drawbacks such as poor electrical conductivity due to the presence of epoxide, carboxyl, and hydroxyl groups on the graphene sheets. ${ }^{2}$ Further, the reduction of GO to graphene needs insalubrious chemical reductants such as hydrazine or sodium borohydride, and high temperature heating in order to recover the graphitic structure. ${ }^{25}$ Moreover, the reduction process cannot completely remove the many structural defects introduced by the oxidation process. A few environmentally friendly processes are available to reduce GO to graphene either by chemical or electrochemical methods, but these give low yield. ${ }^{26}$ Thus despite the usefulness of previous graphene synthetic methods, none appear economical, eco-friendly, kilogram scale production of the material.

Here we report a novel, cost-effective and eco-friendly, one-step method that involves controlled gas-phase hydrocarbon $\left(\mathrm{C}_{2} \mathrm{H}_{2}\right)$ detonation with oxygen $\left(\mathrm{O}_{2}\right)$ for the production of graphene nanosheets. Our process has several advantages such as simplicity, high productivity, economic viability, and short synthesis time (minute). This method is catalyst-free and does not generate any toxic by-products during synthesis as generated in solution phase methods. ${ }^{20-24}$

\section{Experimental details}

Graphene nanosheets (GNs) in the form of a powder were prepared from the catalyst-free controlled detonation of $\mathrm{C}_{2} \mathrm{H}_{2}$ gas in the presence of $\mathrm{O}_{2}$ in a 16.6 liter cylindrical aluminum chamber. The pre-detonation molar ratios of $\mathrm{O}_{2} / \mathrm{C}_{2} \mathrm{H}_{2}$ were $0.4,0.5,0.6,0.7$, and 0.8. For each 
ratio, the initial chamber pressure was 1 atmosphere. The gases had purities of $98.0 \%$ for $\mathrm{C}_{2} \mathrm{H}_{2}$ and $99.0 \%$ for $\mathrm{O}_{2}$. In a typical batch, the detonation of $\mathrm{C}_{2} \mathrm{H}_{2}$ with $\mathrm{O}_{2}$ was carried out by a controlled power supply through a spark generator ignition system (Fig.S1and S2, where S refers supplementary information). During the detonation, the hydrocarbon was first converted into free carbon atoms or ions which condensed into a nanoparticle carbon aerosols which in turn quickly aggregated and then finally formed a gel, known as a Carbon Aerosol Gel (CAG). ${ }^{27}$ After the denotation, the chamber was allowed to cool to $300 \mathrm{~K}$. The fluffy black CAG powder was collected from the chamber (inset Fig. 5); we will henceforth call this material "detonation carbon". The material was homogeneous and subsequent characterization confirmed that it was one phase. The detonation pressure and temperature were measured with a data acquisition system. The same process was followed for all molar ratios. Table 1 shows the peak temperature and the pressure observed during detonation for different $\mathrm{O}_{2}: \mathrm{C}_{2} \mathrm{H}_{2}$ molar ratios. These high pressures and temperatures (ca. 4000K), which are a consequence of the exothermic detonation of the hydrocarbon and oxygen, last for about 15 milliseconds during the detonation, after which the system rapidly cools (Fig. S2). The phase, layered structure, and the chemical compositions of detonation carbon was analyzed by XRD, TEM, Raman spectroscopy and X-ray Photoelectron spectroscopy.

\section{Characterizations}

X-ray diffraction was carried out using a Bruker D8 Advance X-ray diffractometer, Germany, with nickel filter $\mathrm{Cu} \mathrm{K} \alpha$ radiation as the X-ray source to determine phase purity and degree of crystallization. The morphology and the size of the samples were determined with a FEI Company Nova NanoSEM 430 field emission scanning electron microscope, FESEM, at 3.5 $\mathrm{kV}$ and low vacuum with a TLD detector and Philips CM-100 transmission electron microscope (TEM) with an accelerating voltage of $100 \mathrm{kV}$. For TEM measurement, the samples were prepared by inserting $\mathrm{Cu}$ grids in the detonation carbon powder without using any solvent. The high resolution TEM images and SAED patterns were recorded by using FEI Tecnai F20 XT Field Emission Transmission Electron Microscope with an accelerating voltage of $200 \mathrm{kV}$. BET measurements were carried out using a Nova 1000 series surface area analyzer, Quantachrome instrument. Diffuse reflectance FTIR spectra were recorded via a Cary 630 FTIR spectrophotometer, Agilent Technology, USA over a range 500-4000 $\mathrm{cm}^{-1}$. The X-ray 
photoelectron spectroscopy (XPS) of a Perkin-Elmer PHI 5400 spectrometer with Al Ka X-ray source $(1486.6 \mathrm{eV})$ was used to obtain the chemical compositions of the samples. The spectrometer was calibrated using $\mathrm{Au} 4 \mathrm{f}_{7 / 2}$ at $84.0 \mathrm{eV}$ and $\mathrm{Cu} 2 \mathrm{p}_{3 / 2}$ at $932.7 \mathrm{eV}$. The base pressure of the analysis chamber was below $10^{-9}$ mbar. The room temperature Raman spectra were obtained on pellets of $10 \mathrm{~mm}$ diameter and $2 \mathrm{~mm}$ thick (as shown in the inset of Fig. 8) with an iHR550 Raman spectrophotometer, Horiba Jobin Yvon with a HeNe laser (632.8 nm) as the excitation source.

\section{Results and discussion}

The X-ray diffraction (XRD) patterns of the detonation carbon obtained at $\mathrm{O}_{2} / \mathrm{C}_{2} \mathrm{H}_{2}$ of 0.4, 0.5, 0.6, 0.7, and 0.8 and graphite flakes (GF, obtained from Alfa Aesar for comparison) are depicted in Fig. 1. Fig. 1(a) shows seven well defined diffraction peaks that are characteristic of graphite with the most intense (002) peak centered at $26.6^{\circ}$ (enlarged in the inset), while the (002) peak of the detonation carbon is centered at $26.05^{\circ}$ [Fig. 1(b)-(f)] to imply an interplanar spacing $(d)$ of $0.341 \mathrm{~nm}$, which is larger than $d=0.335 \mathrm{~nm}$ of GF. The determined $d=0.341 \mathrm{~nm}$ for the detonation carbon is in good agreement with the XRD pattern reported for pristine GNs synthesized by other methods. ${ }^{28,29}$ Hence, the detonation carbon resembles the graphitic (graphene) structure. In addition, the reduction in full width at half maxima (FWHM) of the (002) peak with increasing $\mathrm{O}_{2} / \mathrm{C}_{2} \mathrm{H}_{2}$ ratio indicates an increased size of the crystallite and, thus, more crystalline order.

Figure 2 (a-e) shows TEM images of the detonation carbon powder obtained at different $\mathrm{O}_{2} / \mathrm{C}_{2} \mathrm{H}_{2}$ gas ratios. All images reveal that the layers in detonation carbon are transparent, crumpled, folded, and randomly stacked on each other. They show a laminar morphology with crumpling consistent with the structure of pristine two-dimensional graphene prepared by other methods. ${ }^{28-30}$ This crumpling is intrinsic to graphene sheets because a thermodynamically unstable two-dimensional sheet undergoes microscopic crumpling via bending or buckling to get thermodynamically stable three-dimensional structures in localized regions. ${ }^{31}$ In Fig. 2(a, b), the detonation carbon prepared with $\mathrm{O}_{2} / \mathrm{C}_{2} \mathrm{H}_{2}=0.4$ and 0.5 , respectively, show transparent ramified fractal aggregates of GNs. These aggregates have dense regions about 35-55 $\mathrm{nm}$ size connected by thin, continuous, twisted, ribbon-like structures [see Fig. S3(a, b)]. This implies that the detonation carbon consists of GNs interlaced with one another. With increasing ratios from 0.6 to 
0.8, the GNs show a distinct feature of nearly spherical shape with an increased size of about 225-250 nm [Fig. 2(c-e) and S3(c-e)]. The similar layer morphology stacked over each other around 250-350 nm size of the GNs powder prepared from $\mathrm{O}_{2} / \mathrm{C}_{2} \mathrm{H}_{2}$ of 0.8 is observed in FESEM as shown in Fig. S4. The $\mathrm{O}_{2} / \mathrm{C}_{2} \mathrm{H}_{2}$ ratio dependence of GNs size observed in TEM images is consistent with the (002) peak widths in the XRD spectra [Fig. 1(b)-(f)]. Thus, the detonation carbon appears to be composed of GNs and will hereafter be referred to as such as well. Moreover, in the samples of lower $\mathrm{O}_{2} / \mathrm{C}_{2} \mathrm{H}_{2}$, the randomly oriented GNs [Fig. 2(a-b)] exhibit many thin layers entangled with each other with overlapped edges, while more ordered stacking of GNs in mostly two to three layers is observed for the samples of higher $\mathrm{O}_{2} / \mathrm{C}_{2} \mathrm{H}_{2}$ as seen in Fig. 2(c-e). The HRTEM image of the edge of the GNs in Fig. 2(f) shows the layer structure more closely.

High magnification TEM images and the SAED patterns of the GNs of selected regions are shown in Fig.3. The transparent and featureless regions, indicated by arrows in Fig. 3 (a and d), are likely to be monolayer graphene which tends to scroll at the edges. The SAED patterns in Fig. 3(b, c and f) confirm the crystalline structure of the GNs. The diffraction patterns of the region marked with 'A' and ' $C$ ' in Fig. 3(a and e) show six-fold symmetry \{see Fig. 3(b and f)\} similar to monolayer graphene, whereas the region marked with ' $B$ ' in Fig. 3(a) shows misaligned diffraction spots in tiny arc shapes representing randomized six-fold symmetry as shown in Fig. 3(c). The misaligned spots could probably be due to crumpled local regions in GNs. The HRTEM images of GNs depicted in Fig. S3(f) shows the lattice fringes spacing of $0.240 \mathrm{~nm}$ which is in good agreement with the in-plane lattice constant of $0.246 \mathrm{~nm}$ for graphite. $^{32}$

The Brunauer-Emmett-Teller (BET) specific surface area (SSA) of the GNs measured from $\mathrm{N}_{2}$ adsorption desorption isotherms at $77 \mathrm{~K}$ is shown in Fig. 4. The isotherms exhibit typeII pattern and type H3 hysteresis loop. The adsorption hysteresis suggests that the isotherm is a pseudo type-II pattern due to multi-layer adsorption in materials having slit-like pores or aggregates of platy particles. ${ }^{33}$ In graphene, adsorption occurs on the surface of the graphene sheets, but due to their few layered structure, slit-like open pores exist. These open pores are responsible for the hysteresis loop observed in graphene materials. ${ }^{34}$ From the linear region of the graph and using the BET equation, it is found that the SSA lies in between 23 to $187 \mathrm{~m}^{2} \mathrm{~g}^{-1}$ 
(Fig. 5), which is significantly lower than the theoretical SSA of $2630 \mathrm{~m}^{2} \mathrm{~g}^{-1}$ for individual isolated graphene sheets. ${ }^{35}$ However, the SSA of the detonation carbon prepared at $0.4 \mathrm{O}_{2} / \mathrm{C}_{2} \mathrm{H}_{2}$ is close to the previously reported SSA-value of $184 \mathrm{~m}^{2} \mathrm{~g}^{-1}$ for GNs. ${ }^{36}$ A significant finding is that the yield per detonation of the GNs is high, in the range of $38 \%$ to $66 \%$ as shown in Fig. 5. It is found that the mass of the GNs is decreased as the amount of $\mathrm{O}_{2}$ is increased in the gaseous mixture.

The Drifts-FTIR measurement was performed to explore the surface functional groups present on GNs produced by detonation. Figure 6 displays the Drifts-FTIR spectra of detonation carbon prepared with different $\mathrm{O}_{2} / \mathrm{C}_{2} \mathrm{H}_{2}$ ratio. As the production method involves $\mathrm{C}_{2} \mathrm{H}_{2}$ and $\mathrm{O}_{2}$, one might expect some carboxyl or epoxy groups and hydrogen attached to the surface of GNs. However, the spectra (Fig. 6) do not show any features of functional group attached to the surface of the detonation carbon GNs, suggesting its pristine nature. The chemical composition of GNs is further explored by X-ray Photoelectron Spectroscopy (XPS). The XPS spectra of graphene GNs obtained after detonation of $\mathrm{O}_{2} / \mathrm{C}_{2} \mathrm{H}_{2}$ of 0.4 is presented in Fig 7. The survey XPS spectrum in Fig 7(a) indicates that the graphene is very pure because the actual ratio of $\mathrm{C}$ to $\mathrm{O}$ is about 49:1. Since XPS measures the composition on the sample surface, the presence of trace oxygen in the survey spectrum can be influenced by the moisture absorption on the surface from the atmosphere. ${ }^{37-39}$ However, the enlarged view of the $\mathrm{C}$ 1s spectrum presented in Fig. 7(b) shows a single peak around $284.8 \mathrm{eV}$, which is associated with graphitic carbon. Moreover, the asymmetry in the peak is due to structural disorder at the edges of the $s p^{2}$ network in graphene where the plane of carbon and any carbon fragments could be interacting by the surface oxygen attached during the transfer of the sample to the XPS instrument. No additional signals are observed (see Fig. S5 for XPS of $\mathrm{O}_{2} / \mathrm{C}_{2} \mathrm{H}_{2}$ of 0.8 as well) to imply that no other functional groups are attached with the C-C system of GNs. This is consistent with the FTIR data mentioned above. These results confirm the one-phase, pristine nature of the GNs produced here.

The structure and quality of the detonation carbon GNs were analyzed by using Raman spectroscopy. Figure 8 shows the Raman spectra of GF and the detonation carbon GNs measured at an excitation wavelength of $632.8 \mathrm{~nm}$ under ambient conditions. Figure 8(a) presents characteristic G- and 2D-bands of GF at 1584 and $2690 \mathrm{~cm}^{-1}$, respectively, and the absence of defect (D) band indicates that GF are almost defect free. The sharp G-band at $1584 \mathrm{~cm}^{-1}$ 
corresponds to an optical $\mathrm{E}_{2 \mathrm{~g}}$ phonon at the Brillouin Zone center of all $\mathrm{sp}^{2}$ hybridized carbons, while the 2D-band at $2690 \mathrm{~cm}^{-1}$ corresponds to overtones of the D-band. This band is present even in absence of defects because it is the sum of two phonons with opposite momentum. ${ }^{40,41}$ It is the most prominent feature for graphene in the Raman spectrum, and its position and shape can be used to distinguish between single-layer, double-layer and few-layer graphene with $\mathrm{AB}$ interlayer stacking. ${ }^{30,40}$

As shown in Fig. 8(b-f), the Raman spectra of the detonation carbon GNs show two new bands at 1328 and $1610 \mathrm{~cm}^{-1}$ along with G- and 2D-bands at 1580 and $2650 \mathrm{~cm}^{-1}$. The band at $1328 \mathrm{~cm}^{-1}$ is assigned to the D-band, which is due to an intervalley double resonance (DR) Raman process from the transverse optical modes of K-point phonons of $\mathrm{A}_{1 \mathrm{~g}}$ symmetry in a structural defect or partially disordered structures of the $\mathrm{sp}^{2}$ domains in GNs. ${ }^{40,41}$ The peak at $1610 \mathrm{~cm}^{-1}$ is called the $\mathrm{D}^{\prime}$-band that occurs via an intravalley DR process in the presence of defects. Furthermore, the relative intensity of D-and G-bands is a convenient way to estimate the extent of defects and the size of in-plane $\mathrm{sp}^{2}$ domain in the GNs. ${ }^{31,42}$ An obvious observation is that the intensity of the D-band decreases with increasing $\mathrm{O}_{2}$ content. The intensity ratio of the D- and G-bands $\left(\mathrm{I}_{\mathrm{D}} / \mathrm{I}_{\mathrm{G}}\right)$ in GNs decreases from 1.33 to 0.28 for 0.4 to $0.8 \mathrm{O}_{2} / \mathrm{C}_{2} \mathrm{H}_{2}$ ratio. This indicates that partial $\mathrm{sp}^{2}$ domains are restored at different levels, and the graphitic degree of GNs is also improved accordingly due to the reduction effect and self-repairing of the graphene layer at high $\mathrm{O}_{2}$ content. ${ }^{29}$ The shape of the $2 \mathrm{D}$-band is $\mathrm{O}_{2}$ content dependent. At $0.4 \mathrm{O}_{2} / \mathrm{C}_{2} \mathrm{H}_{2}$, the $2 \mathrm{D}$ band is broad to imply many layers of GNs, as is also evident from TEM images in Fig. S3 (a). The width gradually decreases from 65 to $43 \mathrm{~cm}^{-1}$ (see Fig. S6) with increasing $\mathrm{O}_{2}$ content, becoming sharpest for $0.8 \mathrm{O}_{2} / \mathrm{C}_{2} \mathrm{H}_{2}$. This evolution of sharpness of the 2D-band implies the transformation of GNs from many layers to two to three layers with increasing $\mathrm{O}_{2}$ content (the width of the $2 \mathrm{D}$ band for monolayer graphene is $\left.24 \mathrm{~cm}^{-1}\right)$. ${ }^{43}$ Hence, it can be concluded that $\mathrm{O}_{2}$ plays a vital role for GNs quality in this particular process.

The question remains why graphene is created in this detonation process instead of normal carbonaceous soot. The mechanism of graphene production is undoubtedly as difficult to describe as the mechanism of soot formation in flames, a description which remains incomplete. ${ }^{44}$ However, an important clue to a description might lie in Table 1 which shows the peak temperatures and pressures observed during detonation for the different molar ratios of 
$\mathrm{O}_{2} / \mathrm{C}_{2} \mathrm{H}_{2}$ used. No functionality with molar ratio is observed beyond the estimated errors of the measurements. These temperatures and pressures are consistent with each other under the assumption of no change in the total moles of gas in the chamber from before detonation, at ca. $300 \mathrm{~K}$ and $1 \mathrm{~atm}$, to the peak temperature. The peak detonation temperature of about $4000 \mathrm{~K}$ is roughly twice the combustion temperature of sooting hydrocarbon/air diffusion flames including $\mathrm{C}_{2} \mathrm{H}_{2}{ }^{45}$ The "normal" soot produced in such flames consists of roughly spherical monomers (primary particles) with diameters in the range of 20 to $50 \mathrm{~nm}$ joined together into fractal aggregates. $^{46,47}$ The composition of these monomers is typically mostly carbon with a carbon/hydrogen ratio of $\mathrm{C} / \mathrm{H} \approx 8$, and the carbon is nearly amorphous being composed of many small graphitic planes. ${ }^{45}$ In strong contrast detonation carbon is pure carbon with graphene morphology and characteristics; it is graphene. Based on our temperature measurements we propose that the key difference is the temperature. This hypothesis is supported by the observations of Choi and coworkers. ${ }^{48}$ They used a burner arrangement in which $\mathrm{C}_{2} \mathrm{H}_{2}$ co-flowed with an annular oxyhydrogen flame. This flame produced normal soot. The flame was irradiated with a many watt $\mathrm{CO}_{2}$ laser. Sharply above a laser power threshold the flame stopped producing normal soot and instead produced "shell-shape carbon nanoparticles" composed of grapheniclike curved layers wrapped together. Concomitant with this threshold, the flame temperature jumped from $2100 \mathrm{~K}$ to $3000 \mathrm{~K}$. Although these observations are unexplained, their similarity to our detonation process in temperature and resulting morphologies supports our hypothesis that the high temperatures $(>3000 \mathrm{~K})$ during detonation is the fundamental cause of the graphenic nature of the carbon produced. Given these observations, we further hypothesize that high temperature, such as $4000 \mathrm{~K}$, completely decomposes the hydrocarbon precursor to yield carbon atoms or ions which then rapidly combine after the high temperature phase to form graphene. This is very different than the current view of normal soot formation in a flame which describes soot formation as a chemical process involving molecular polymerization up a chain of polyaromatic hydrocarbons followed by dehydrogenation to $\operatorname{soot}^{44}$. Finally, if this hypothesis is true, detonation of other hydrocarbons should yield graphene materials as well; a proposition we will soon pursue. 


\section{Conclusions}

In summary, a simple, quick, one-step, eco-friendly, high-yield method for the gram scale production of graphene nanosheets has been developed. The method involves the controlled detonation of $\mathrm{C}_{2} \mathrm{H}_{2}$ in presence of $\mathrm{O}_{2}$. The high temperature of the detonation, ca. $4000 \mathrm{~K}$, is proposed as the cause of graphene production rather than normal soot. This method is green and does not result in contamination of the graphene product. Simple modification of our lab-scale apparatus could produce 300 grams/hour. Thus, with scale up, this method can produce graphene nanosheets in the large quantities required for industrial application.

\section{Acknowledgments}

We thank Prof. K. J. Klabunde for use of his XRD and BET instruments and also thank Dr. Daniel L. Boyle for TEM and FESEM and Dr. David Moore, KU for HRTEM measurement, Prof. Keith L. Hohn and Myles Ikenberry for XPS and Dr. Leila Maurmann for FTIR. We also thank to DST, New Delhi, Govt. of India, for providing opportunity to Dr. G. P. Singh to visit KSU under BOYSCAST fellowship. This research was partially funded by KSU targeted excellence.

\section{Address}

*Department of Physics, Kansas State University, Manhattan, Kansas-66506, USA, Tel: 1-785532-1626,E-mail: sor@phys.ksu.edu

Supplementary Information (S) available: Experimental set-up and other information on GNs.

\section{References}

[1] Katsnelson M I 2007Mater. Today 10, 20

[2] Ruoff R 2008 Nat. Nanotechnol 3, 10

[3] Geim A K 2009 Science 324, 1530

[4] Lin Y M, Jenkins K A, Garcia A V, Small J P, Farmer D B and Avouris P 2009 Nano Lett. 9, 422

[5] Schedin F, Geim A K, Morozov S V, Hill E W, Blake P, Katsnelson M I, and Novoselov K S 2007 Nat. Mater. 6, 652 
[6] Mohanty N and Berry V 2008 Nano Lett. 8, 4469

[7] Stankovich S, Dikin D A, Dommett G H B, Kohlhaas K M, Zimney E J, Stach E A, Pinen R D, Nguyen S T and Ruoff R S 2006 Nature 442, 282

[8] Watcharotone S, Dikin D A, Stankovich S, Piner R, Jung I, Mommett G H B, Evmenenko G, Wu S E, Chen S F and Liu C P 2007 Nano Lett. 7, 1888

[9] Takamura T, Endo K, Fu L, Wu Y P, Lee K J and Matsumoto T, 2007 Eletrochim. Acta, 53, 1055

[10] Geim A K and Novoselov K S 2007 Nat. Mater. 6, 183

[11] Novoselov K S, Jiang D, Schedin F, Booth T J, Khotkevich V V, Morozov S V and Geim A K 2005 Proc. Natl. Acad. Sci. U.S.A. 102, 10451

[12] Charrier A, Coati A, Argunova T, Garreau Y, Pinchaux R, Forbeaux I, Debever J M, Sauvage-Simkin M and Themlin J M 2002 J. Appl. Phys. 92, 2479

[13] Berger C, Song Z M, Li X B, Wu X S, Brown N, Naud C, Mayou D, Li T B, Hass J and Marchenko A N 2006 Science 312, 1191

[14] Hernandez Y, Nicolosi V, Lotya M, Blighe F M, Sun Z, De S, McGovern I T, Holland B, Byrne M, Gunoko Y K, Boland J J, Niraj P, Duesberg G, Krishnamurthy S, Goodhue R, Hutchison J, Scardaci V, Ferrari A C and Coleman J N 2008 Nat. Nanotechnol. 3, 563

[15] Rutter G M, Crain J N, Guisinger N P, Li T, First P N and Stroscio J A, 2007 Science, 317, 219

[16] Zhu C, Guo S, Fang Y and Dong S 2010 ACS Nano 4, 2429

[17] Chen G H, Wenig W G, Wu D and Wu C L 2003 Eur. Polym. J. 39, 2329

[18] Chen G H, Wenig W G, Wu D and Wu C L 2003 Polymer 44, 1781

[19] Dato A, Radmilovic V, Lee Z, Phillips J and Frenchlach M 2008 Nano Letters 8, 2012

[20] Bae S, Kim H, Lee Y, Xu X, Park J-S, Zheng Y, Balakrishnan J, Lei T, Kim H R, Song Y I, Kim Y-J, Kim K S, Ozyilmaz B, Ahn J-H, Hong B H and Iijima 2010 Nat. Nanotechnol. 5, 574.

[21] Park S and Ruoff R S 2009 Nat. Nanotechnol. 4, 217

[22] Park S, An J, Jung I, Piner R D, An S J, Li X, Velamakanni A and Ruoff R S 2009 Nano Lett. 9, 1593

[23] Gomez-Navarro C, Weitz R T, Bittner A M, Scolari M, Mews A, Burghard M and Kern K 2009 Nano Lett. 9, 2206 
[24] Green A A and Hersam M C 2009 Nano Lett. 9, 4031

[25] Stankovich S, Dikin D A, Piner R D, Kohlhaas K A, Kleinhammes A, Jia Y Y, Wu Y, Nguyen S T and Ruoff R S 2007 Carbon 45, 1558.

[26] Guo H L, Wang X F, Qian Q Y, Wang F B and Xia X H 2009 ACS Nano 3, 2653

[27] R. Dhaubhadel, G. S. Gerving, A. Chakrabarti and C.M. Sorensen, Aerosol Sci. Tech. 2007, 41, 804-810.

[28] Wang G, Yang J, Park J, Gou X, Wang B, Liu H and Yao J 2008 J. Phys. Chem. C 112, 8192

[29] Sheng Z H, Chen J J, Bo W J, Wang F B and Xia X H 2011 ACS Nano 5, 4350

[30] Kaniyoor A and Ramaprabhu S 2011 J. Appl. Phys. 109, 124308

[31] Meyer J C, A. K. Geim, Katsnelson M I, Novoselov K S, Booth T J and Roth S 2007 Nature 446, 60

[32] Baskin Y and Meyer L 1995 Phys. Rev. 100, 544

[33] Sing K S W 1995 J. Porous Mater. 2, 5

[34] Wei L, Dai-Ming T, Yan-Bing H, Cong-Hui Y, Zhi-Qiang S, Xue-Cheng C, Cheng-Meng C, Peng-Xiang H, Chang L and Quan-Hong Y 2009 ACS Nano 3, 3730

[35] Stoller M D, Park S J, Zhu Y W, An J H and Ruoff R S 2008 Nano Lett. 8, 3498

[36] Pan D, Wang S, Zhao B, Wu M, Zhang H, Wang Y and Jiao Z 2009 Chem. Mater. 21, 3136

[37] Choucair M, Thordarson P and Stride J A 2009 Nat. Nanotechnol. 4, 30

[38] Tsang S C, Caps V, Paraskevas I, Chadwick D and Thompsett D 2004 Angew. Chem., Int. Ed. 43, 5645-5649

[39] Schniepp H C, Li J-L., McAllister M J, Sai H, Herrera-Alonso M, Adamson D H, Prud'homme R, Car R, Saville D A and Aksay I A 2006 J. Phys. Chem. B 110, 8535

[40] Ferrari A C, Meyer J C, Scardaci V, Casiraghi C, Lazzeri M, Mauri F, Piscanec S, Jiang D, Novoselov K S, Roth S and Geim A K 2006 Phys. Rev. Lett. 97, 187401

[41] Elias D C, Nair R R, Mohiuddin M G, Morozov S V, Blake P, Halsall M P, Ferrari A C, Boukhvalov D W, Katsnelson M I, Geim A K and Novoselov K S 2009 Science 323, 610 
[42] Luo Z, Yu T, Kim K J, Ni Z, You Y, Lim S, Shen Z, Wang S and Lin J 2009 ACS Nano 3, 1781

[43] Malard L M, Pimenta M A, Dresselhause G and Dresselhaus M S 2009 Phys. Reports 473, 51

[44] Frenklach M 2002 Phys. Chem. Chem., Phys. 4, 2028

[45] Gaydon A G and Wolfhard H G 1979 Flames: Their structure, radiation and temperature, Chapman and Hall, London, $4^{\text {th }}$ Edition

[46] Sorensen C M and Feke G D 1996 Aerosol Sci. Tech. 25, 328

[47] Dhaubhadel R, Pierce F, Chakrabarti A and Sorensen C M 2006 Phys. Rev. E 73, 011404

[48] Choi M, Altman I S, Kim Y J, Pikhitsa P V, Lee S, Park G S, Jeong T and Yoo J B 2004 Adv. Mater. 16, 1721 
Table 1: The molar ratio $\mathrm{O}_{2} / \mathrm{C}_{2} \mathrm{H}_{2}$, peak detonation temperature $\left(\mathrm{T}_{\mathrm{d}}\right)$ and pressure $\left(\mathrm{P}_{\mathrm{d}}\right)$ for preparation of GNs.

\begin{tabular}{|c|c|c|}
\hline $\begin{array}{c}\text { Molar ratio } \\
\mathrm{O}_{2} / \mathrm{C}_{2} \mathrm{H}_{2}\end{array}$ & $\begin{array}{c}\mathrm{T}_{\mathrm{d}}(\mathrm{K}) \\
( \pm 200 \mathrm{~K})\end{array}$ & $\begin{array}{c}\mathrm{P}_{\mathrm{d}}(\mathrm{atm}) \\
( \pm 1.5 \mathrm{~atm} .)\end{array}$ \\
\hline 0.4 & 3800 & 13.4 \\
\hline 0.5 & 3900 & 13.1 \\
\hline 0.6 & 4200 & 13.8 \\
\hline 0.7 & 3600 & 14.3 \\
\hline 0.8 & 3800 & 14.3 \\
\hline
\end{tabular}




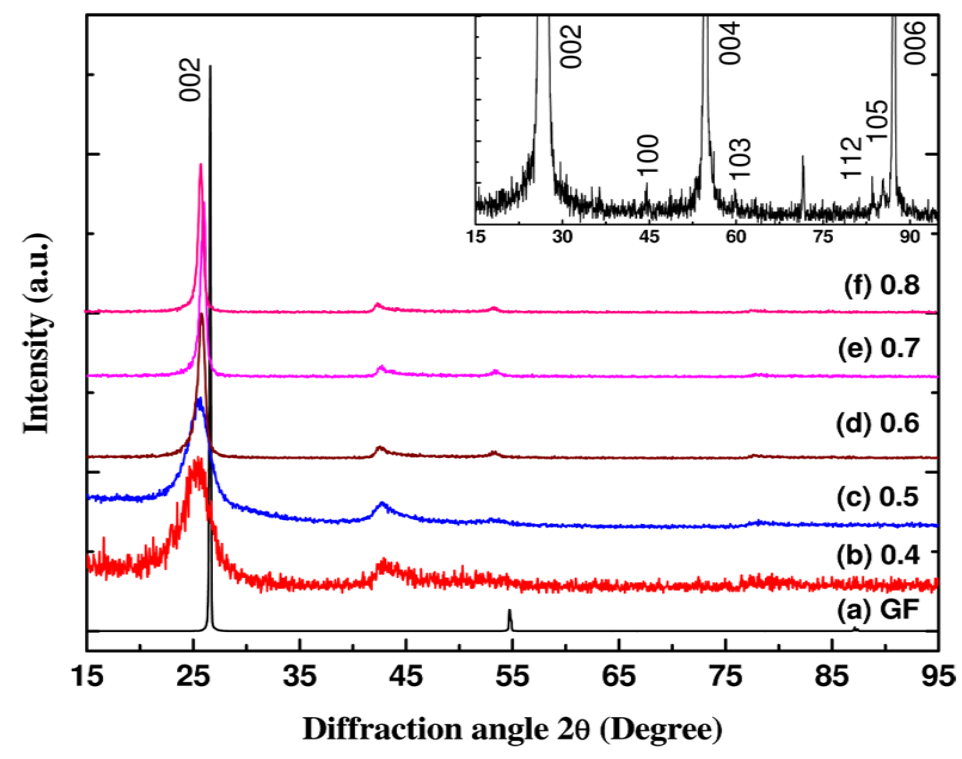

Figure 1: XRD patterns of (a) graphite flakes (GF), and ( $b$ through $f$ ) the detonation carbon graphene nanosheets (GNs) prepared by detonation with different $\mathrm{O}_{2} / \mathrm{C}_{2} \mathrm{H}_{2}$ molar ratios. The magnified spectrum of (a) is shown in the inset. 

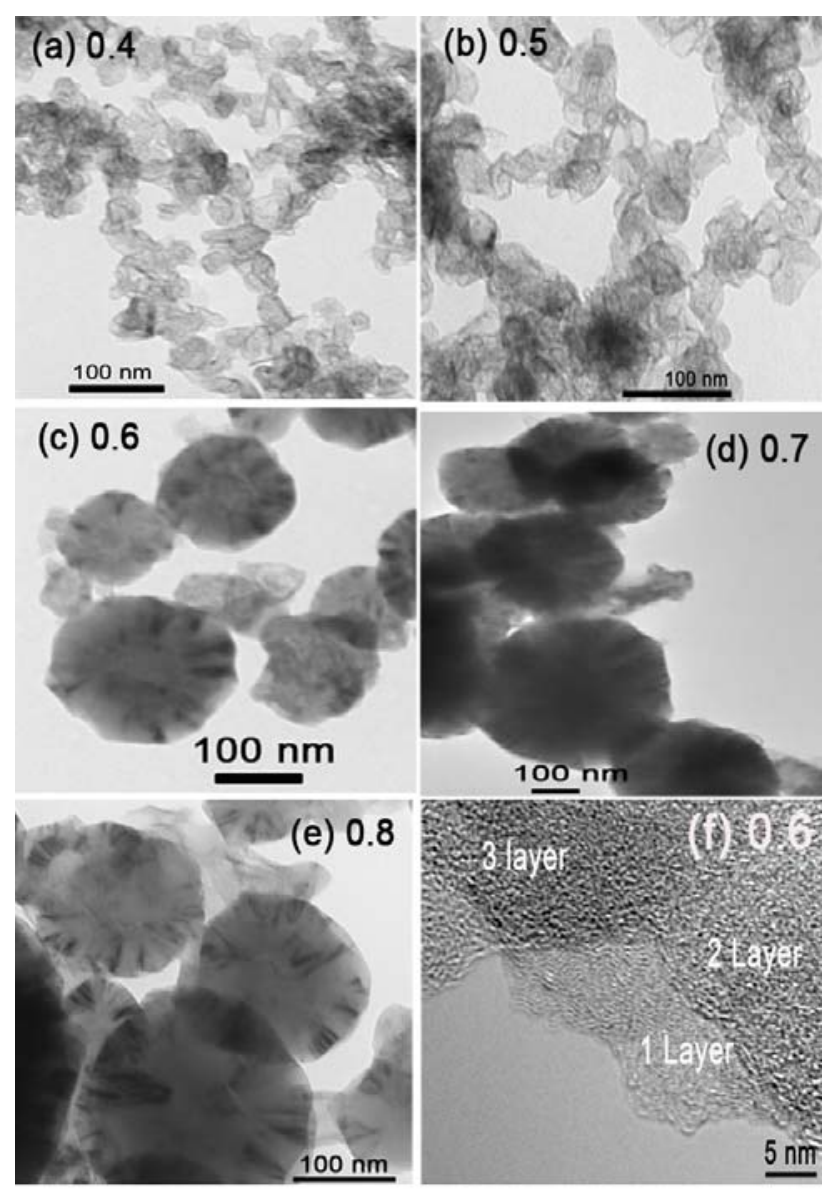

Figure 2: TEM images of GNs prepared by detonation of different molar ratios of $\mathrm{O}_{2} / \mathrm{C}_{2} \mathrm{H}_{2}$ (a-e). (f) HRTEM image of GNs at 0.6 shows well the number of layers. 

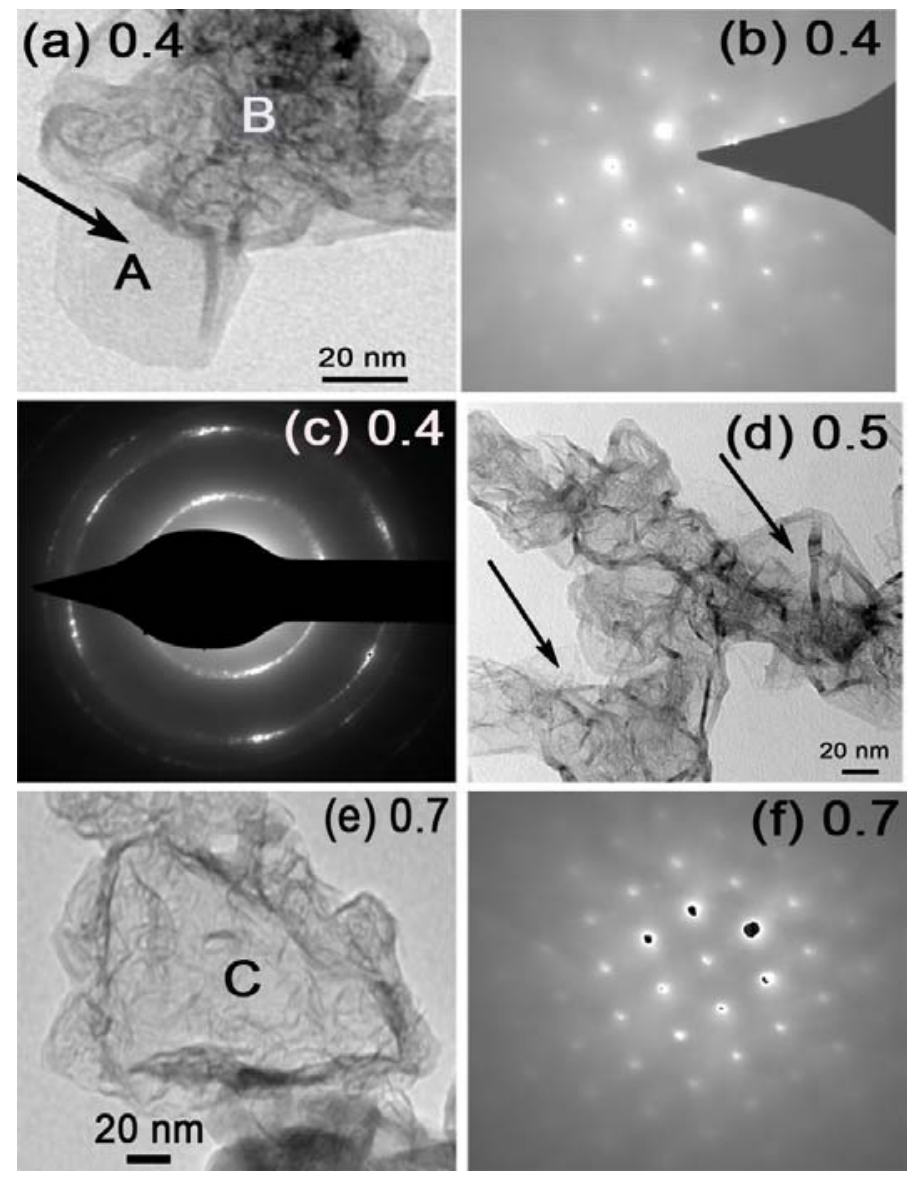

Figure 3: High magnification TEM images and SAED patterns of GNs prepared by detonation of different molar ratios of $\mathrm{O}_{2} / \mathrm{C}_{2} \mathrm{H}_{2}$ (a-f). The SAED patterns of regions marked with 'A', 'B', and ' $\mathrm{C}$ ' are shown in (b), (c) and (f), respectively. Arrows indicate the monolayer GNs. 


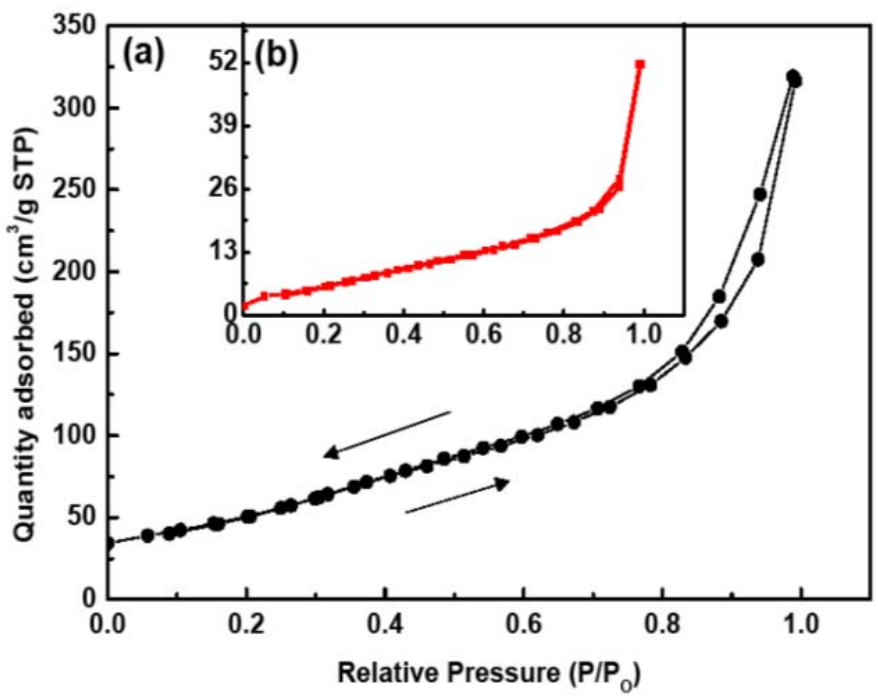

Figure 4: Nitrogen adsorption desorption isotherm of GNs prepared by detonation of $\mathrm{O}_{2} / \mathrm{C}_{2} \mathrm{H}_{2}$ of (a) 0.4 and (b) 0.8 . 


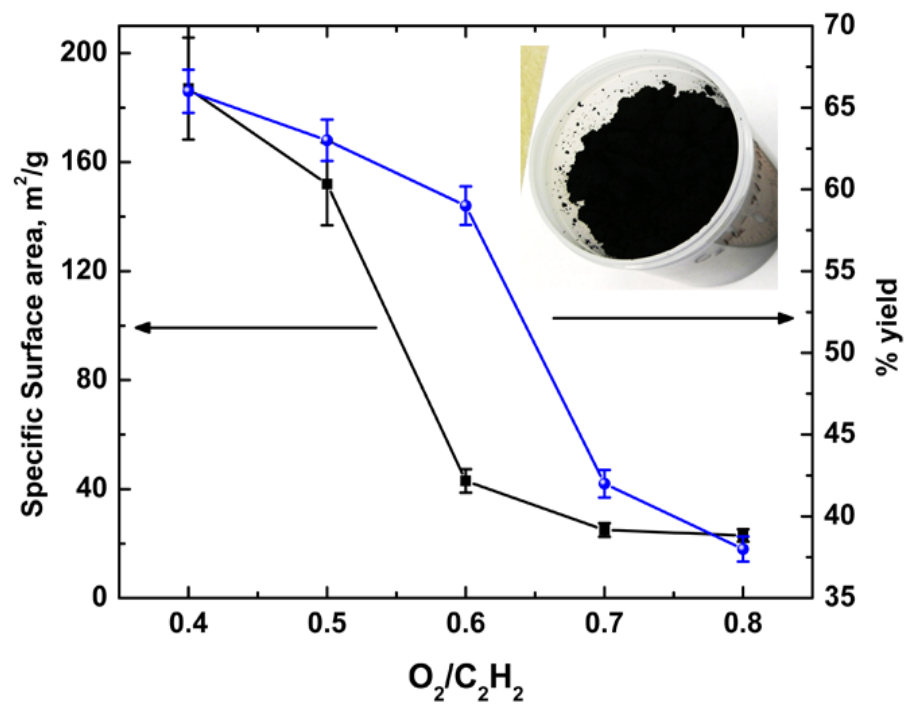

Figure 5: The specific surface area and yield of GNs powder. Lines are guides to the eye. Inset shows the bulk quantity $\sim 7.4 \mathrm{~g}$ graphene powder collected after a detonation 


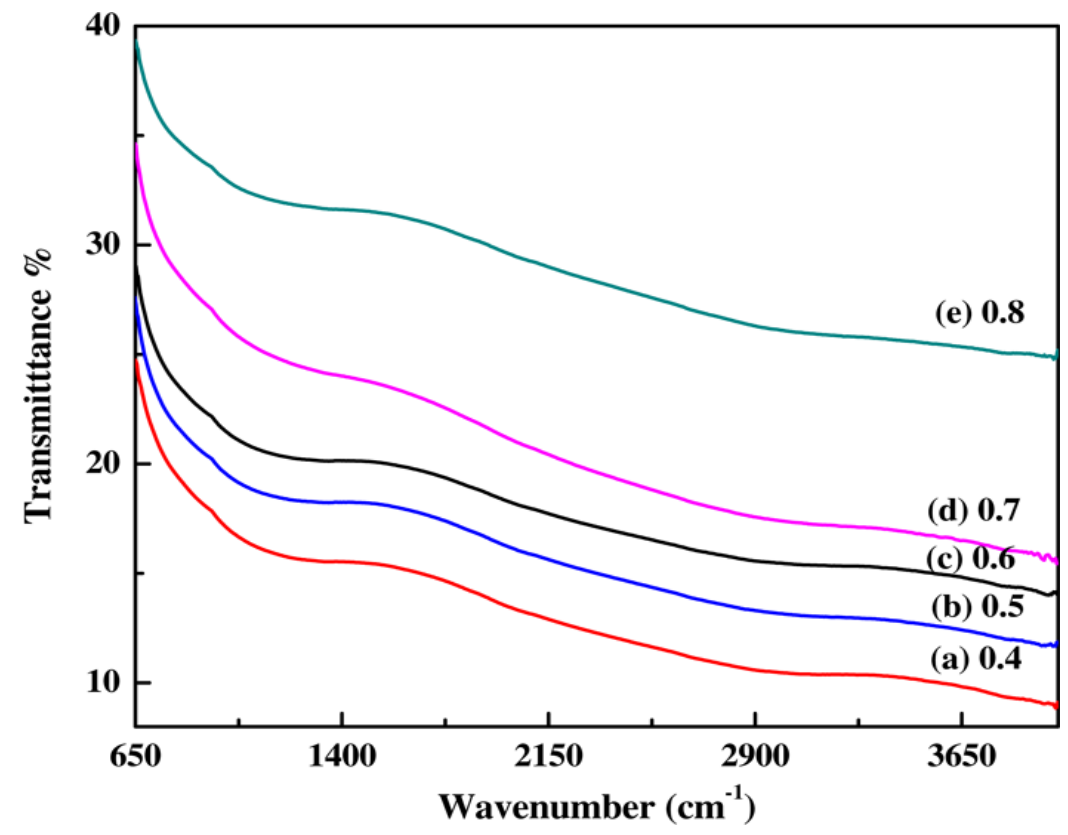

Figure 6: DRIFTS-FTIR spectra of GNs prepared by detonation of different molar ratios of $\mathrm{O}_{2} / \mathrm{C}_{2} \mathrm{H}_{2}$. 

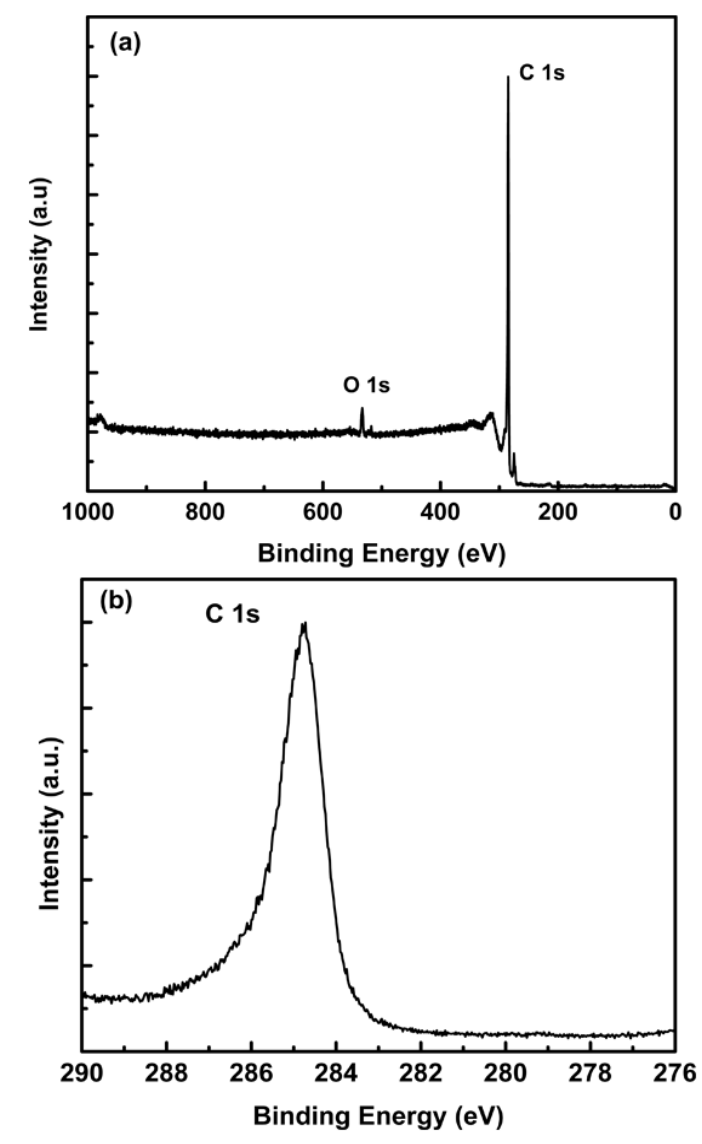

Figure 7: XPS spectra of graphene powder prepared after detonation of $\mathrm{O}_{2} / \mathrm{C}_{2} \mathrm{H}_{2}$ of 0.4 (a) survey and (b) $\mathrm{C}$ 1s spectrum detail 


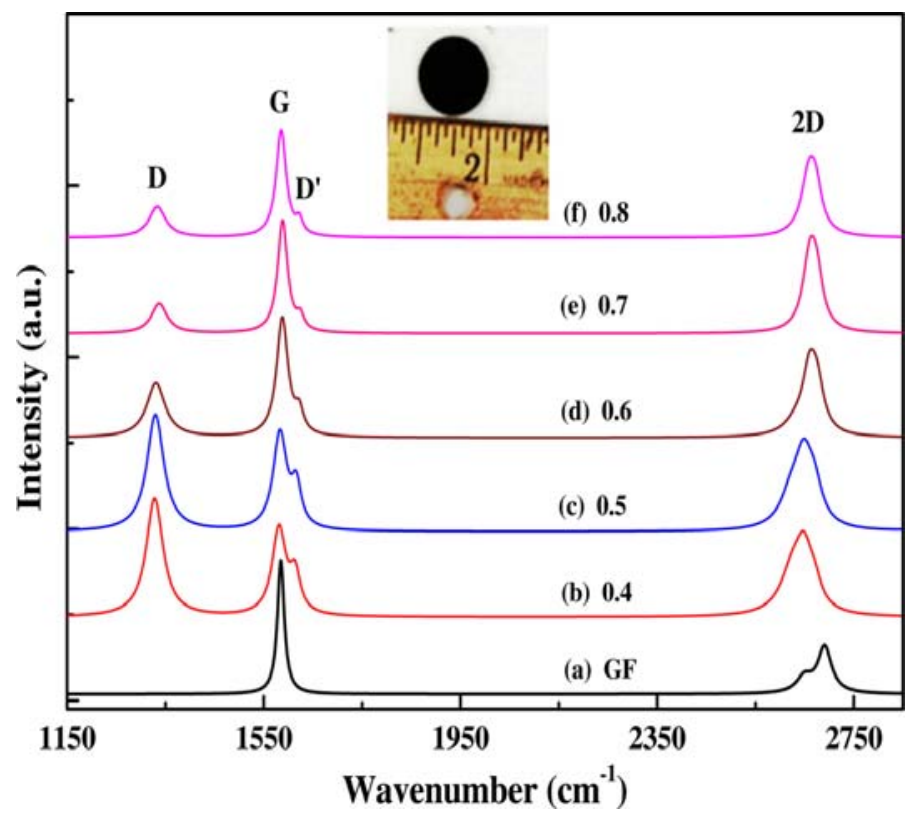

Figure 8: Raman spectra of GF and pristine GNs prepared by detonation of different molar ratios of $\mathrm{O}_{2} / \mathrm{C}_{2} \mathrm{H}_{2}$. The inset shows the pellet form of GNs powder for Raman measurement. 


\title{
One-step synthesis of graphene via catalyst-free gas-phase hydrocarbon detonation
}

\author{
Arjun Nepal, ${ }^{\mathrm{a}}$ Gajendra P. Singh, ${ }^{\mathrm{a}, \mathrm{b}}$ Bret N. Flanders ${ }^{\mathrm{a}}$ and C. M. Sorensen ${ }^{\mathrm{a} *}$
}

${ }^{a}$ Department of Physics, Kansas State University, Manhattan, Kansas-66506, USA, Tel: 1-785532-1626, E-mail: sor@phys.ksu.edu (C. M. Sorensen*), anepal@phys.ksu.edu (Arjun Nepal), bret.flanders@phys.ksu.edu (Bret N.Flanders)

${ }^{\mathrm{b}}$ Centre for Nanotechnology, Central University of Jharkhand, Ranchi-835205, Jharkhand, India, E-mail: gajendrasingh_gs@yahoo.co.in

\section{Supporting Information}

1. Materials and Devices: Graphite flakes (99.99\%, 10 mesh) were purchased from Alfa Aesar. Acetylene $\left(\mathrm{C}_{2} \mathrm{H}_{2}, 98.0 \%\right)$ and Oxygen $\left(\mathrm{O}_{2}, 99.0 \%\right)$ gas were procured from Linweld Lincoln. Data for determining detonation pressure and temperature were acquired by a data acquisition system (DAS), Model: NI USB-6210, National Instruments. A dynamic pressure sensor, Model: 482A21, PCB Piezotronics was used for pressure measurements. Band-pass filters of $515 \mathrm{~nm}$ and $680 \mathrm{~nm}$ wavelengths, and neutral density filter of optical density, OD = 3.0 were purchased from Edmund Optics and implemented into the two-color pyrometer.

\section{Synthesis of graphene nanosheets}

Graphene nanosheets (GNs) in the form of powder were prepared from the detonation of $\mathrm{C}_{2} \mathrm{H}_{2}$ in the presence of $\mathrm{O}_{2}$ in a 16.6 liter cylindrical aluminum chamber equipped with a quartz window of $8.5 \mathrm{~cm} \times 1.5 \mathrm{~cm}$. The molar ratios of $\mathrm{O}_{2} / \mathrm{C}_{2} \mathrm{H}_{2}$ were $0.4,0.5,0.6,0.7$, and 0.8 . For each ratio, the initial chamber pressure was 1 atmosphere. The detonation was carried out by a controlled power supply through a spark generator ignition system connected to an automotive spark plug fitted into the lid of the chamber. The successful detonation was confirmed by a mild 'pop' sound heard after the ignition system was turned on. The detonation pressure was measured with a data acquisition system (DAS) connected to a piezocrystal dynamic pressure sensor installed in 
the lid of the chamber. The detonation temperature was determined by detecting the flash of light that was emitted from the hot soot through the quartz window during the detonation using a twocolor pyrometer. This pyrometer, which was also connected to the DAS, used two band-pass interference filters of $515 \mathrm{~nm}$ and $680 \mathrm{~nm}$ wavelengths. The temperature was calculated from the calibrated ratio of the intensities of the emitted light at these two wavelengths and Planck's black body law under the reasonable assumption that the soot emissivities at these two closely spaced wavelengths are equal. The same process was followed for all molar ratios.

In this type of controlled one-step hydrocarbon detonation method the initial aerosols, the carbon particles formed, are composed of nanometer size monomers. They quickly aggregate and then gel to form a Carbon Aerosol Gel (CAG). ${ }^{1}$ The CAG is found to have very low densities, high surface areas and other useful novel properties. ${ }^{1}$ After detonation, a dark black fluffy CAG layer on the bottom and some clumps here and there clinging to the walls and ceiling of the chamber was obtained. The formation of GNs was confirmed from the XRD, TEM and Raman measurements of CAG.

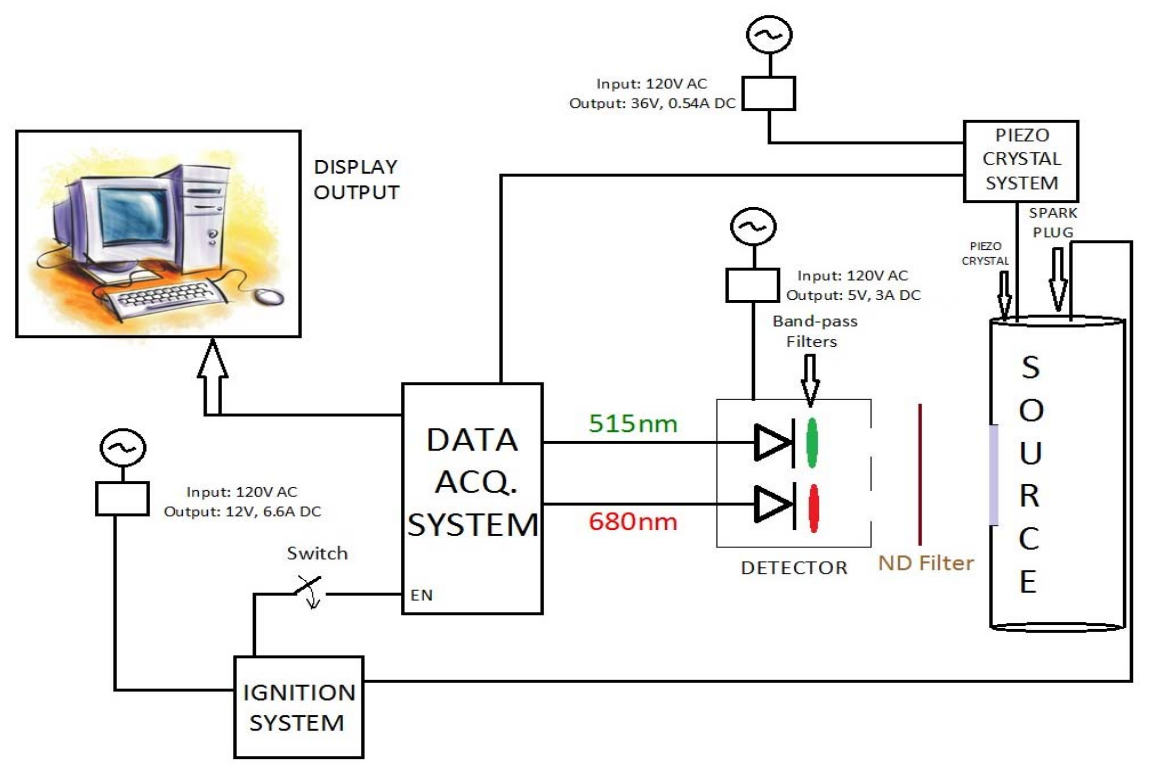

Figure S1: Experimental set-up for hydrocarbon detonation to produce GNs. 


\section{Calibration of pyrometer for temperature measurement}

To measure the detonation temperature a two-color pyrometer was designed and built. The Wein's approximation to the Planck's equation for $\mathrm{T}<6000 \mathrm{~K}$ was used. We assumed that the ratio of emissive power of the carbon particles at two very close wavelengths $\lambda_{1}$ and $\lambda_{2}$ is unity. Then a working formula for the two-color pyrometer is

$$
T_{a}=\frac{-6785}{\ln \left(C \times R_{e x} \times 0.25\right)}
$$

where $T_{a}$ is the actual temperature, $C$ is the calibration constant and $R_{e x}$ is the experimental ratio of the signals of light from $\lambda_{1}=515 \mathrm{~nm}$ and $\lambda_{2}=680 \mathrm{~nm}$.

To determine the calibration constant, the standard terrestrial solar radiation spectrum, Air Mass 1.5 Global, published by American Society for Testing and Materials (ASTM E89287(1992) was used. With the calibration constant so determined, the measured temperature of the sun and tungsten filament lamps were $5600 \mathrm{~K}$ and $3200 \mathrm{~K}$, respectively, with an uncertainty of \pm $200 \mathrm{~K}$.

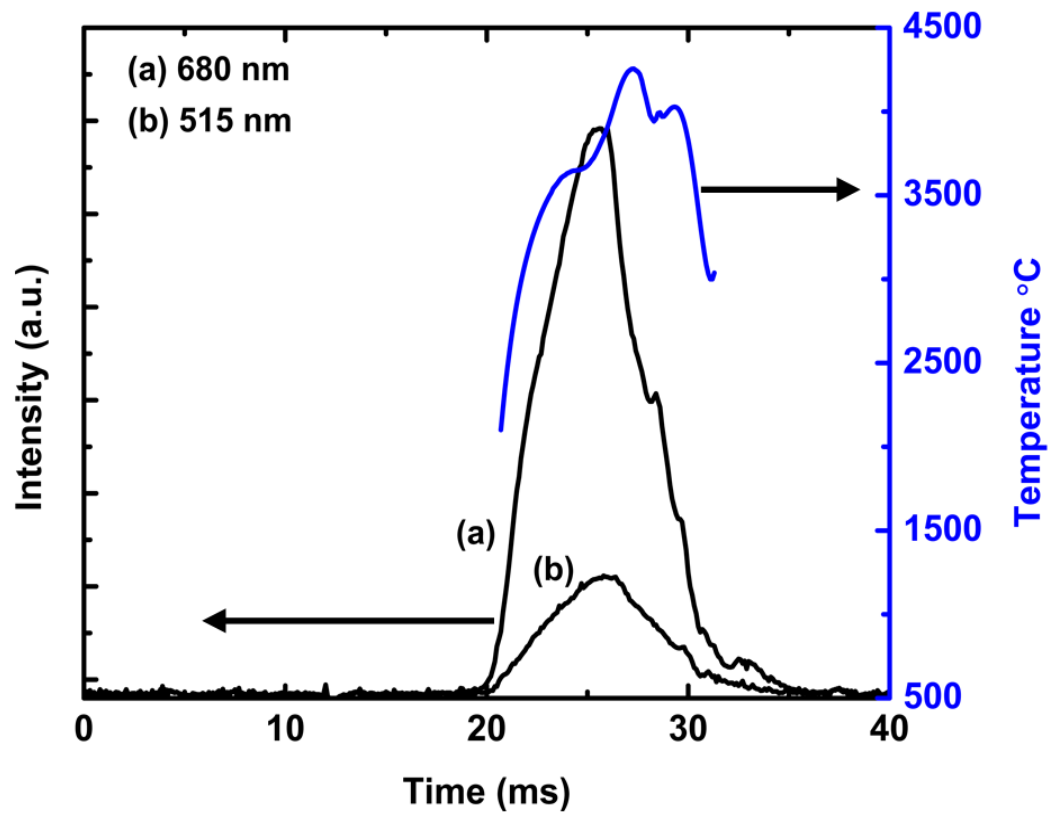

Fig.S2: Signals of intensity of light versus time for a typical detonation acquired by the pyrometer system and the corresponding temperature after the ignition system is turned on 
Figure S2 presents the signal of light intensity versus time after the ignition system is turned on acquired through pyrometer equipped with $515 \mathrm{~nm}$ and $680 \mathrm{~nm}$ filters during the detonation which is completed in $40 \mathrm{~ms}$. When the detonation flash light is higher than the background light, the intensity of the both signals recorded from two filters follow almost the same pattern of the variation with time and it continues for about $15 \mathrm{~ms}$ (see from $20 \mathrm{~ms}$ to $35 \mathrm{~ms}$ in Fig. S2). The temperature of detonation calculated from equation 1 is also plotted in Fig. S2. All the temperatures mentioned in Table 1 correspond to the time where the intensity of both the signals are maximum, and it is around $3900 \pm 200 \mathrm{~K}$ at $26 \mathrm{~ms}$ for the case shown in Fig. S2. Note that in Fig. S2 the maximum temperature appears to be ca. $4200 \mathrm{~K}$ but does not occur at the maximum intensity. This discrepancy is due to the finite experimental error. Temperatures lower than ca. $2000 \mathrm{~K}$ could not be measured accurately with the present pyrometer design. Nevertheless, it is apparent that the rapid cooling from the peak temperature occurs in ca.6 ms. 


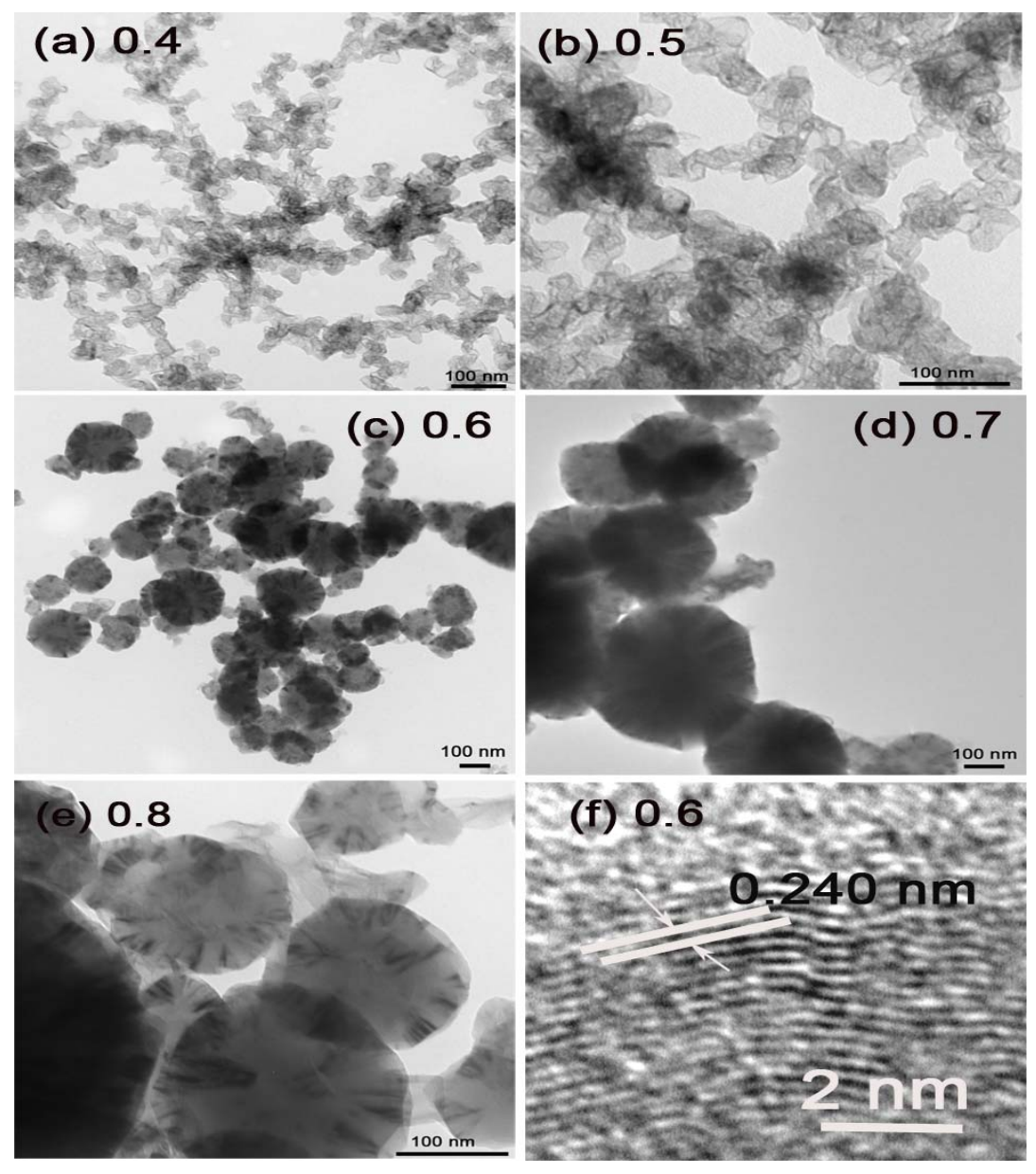

Figure S3: TEM images of GNs prepared by detonation of different molar ratio $\mathrm{ofO}_{2} / \mathrm{C}_{2} \mathrm{H}_{2}$ (a-f). 

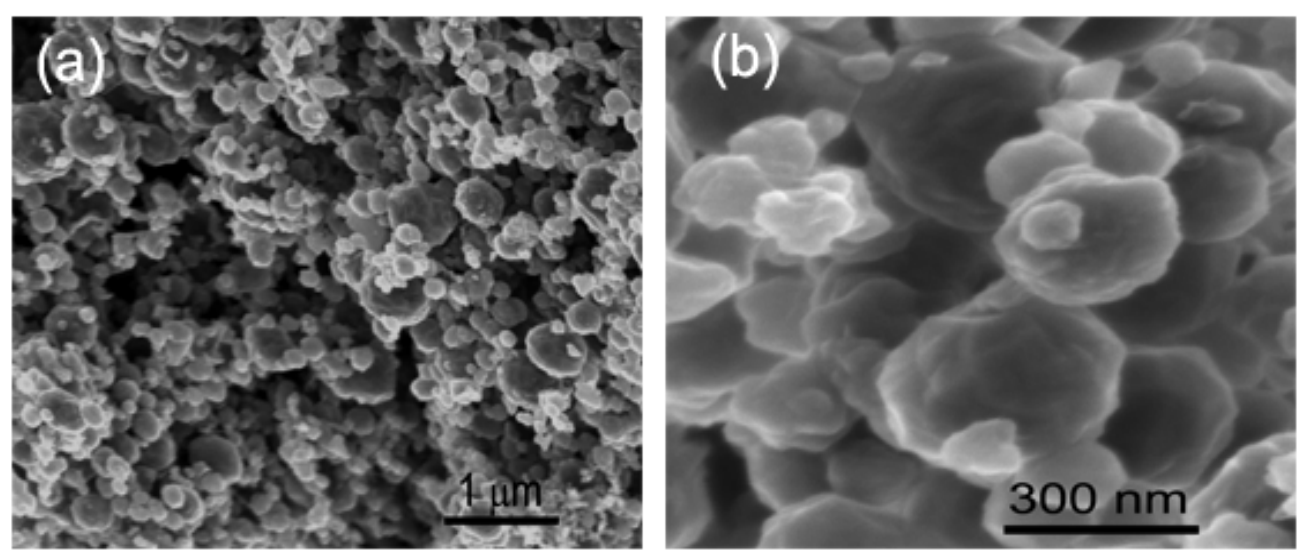

Figure S4: (a) FESEM image of GNs powder prepared by detonation of $\mathrm{O}_{2} / \mathrm{C}_{2} \mathrm{H}_{2}$ of 0.8 and (b) magnified image of (a)
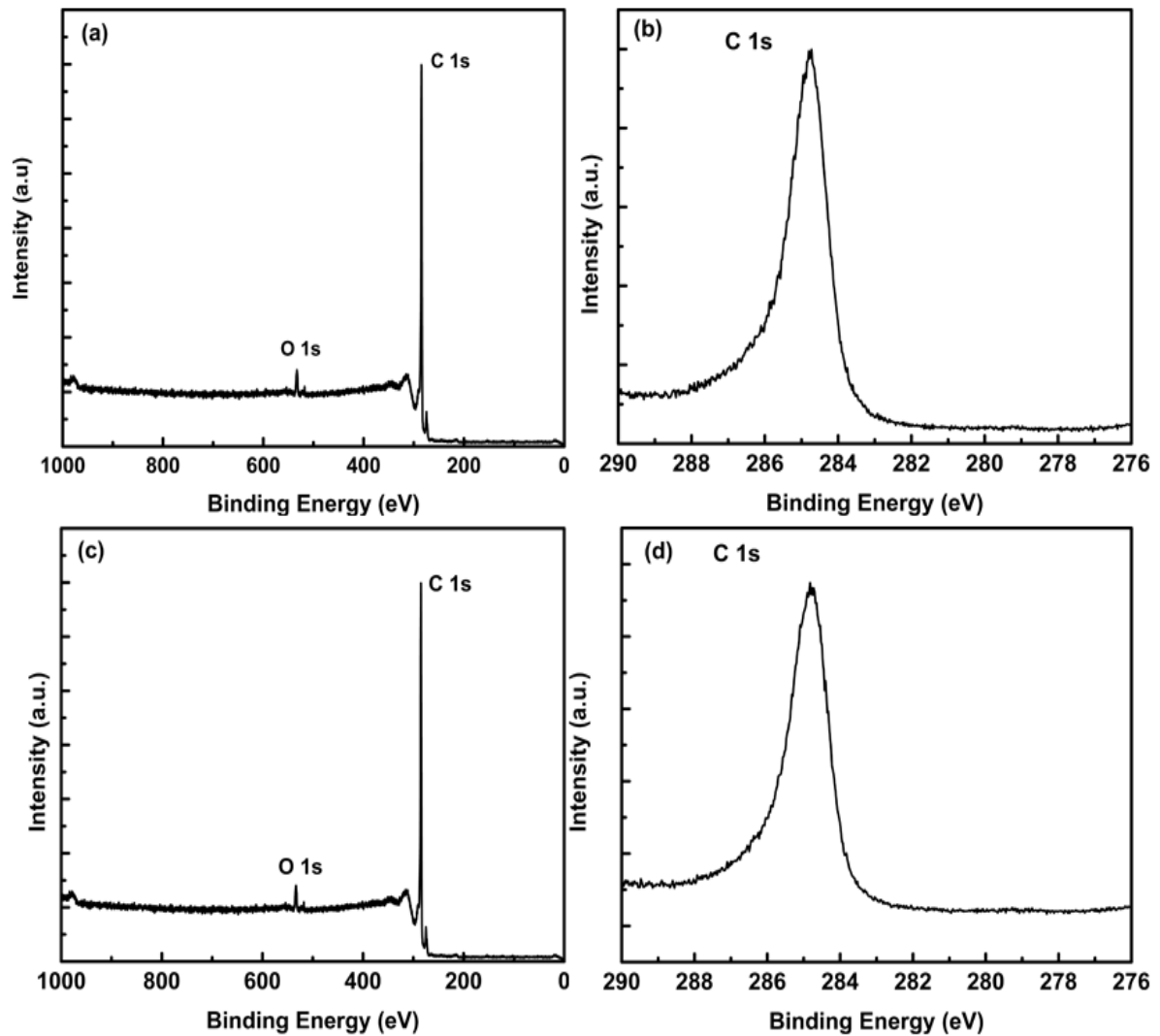

Figure S5: XPS spectra of graphene powder prepared after detonation of $\mathrm{O}_{2} / \mathrm{C}_{2} \mathrm{H}_{2}$ of 0.4 (a) survey and (b) $\mathrm{C} 1 \mathrm{~s}$ and $\mathrm{O}_{2} / \mathrm{C}_{2} \mathrm{H}_{2}$ of 0.8 (a) survey and (b) $\mathrm{C} 1 \mathrm{~s}$. 


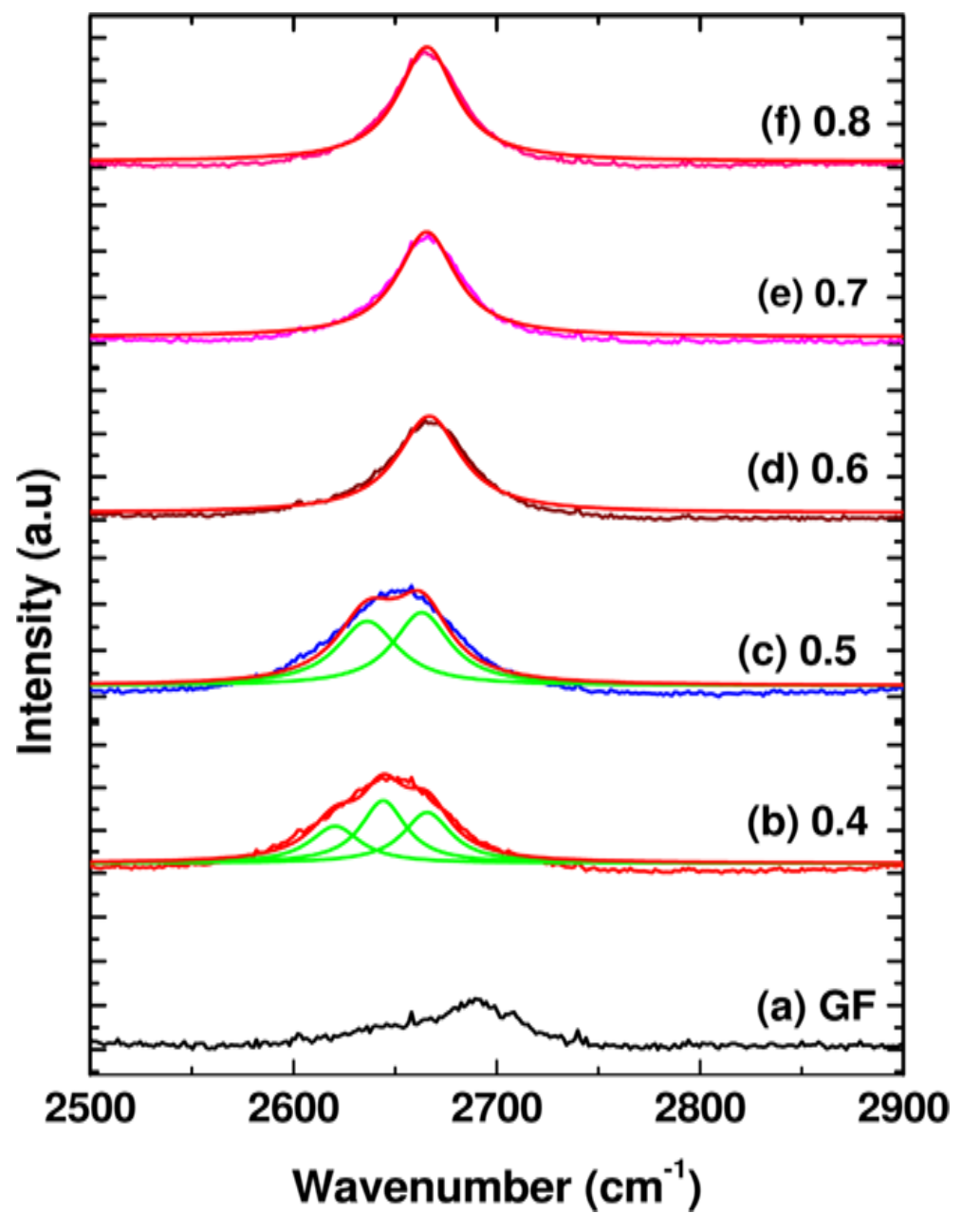

Figure S6: Expanded view of 2D band in Raman spectra of GF and pristine GNs prepared by detonation of different molar ratio of $\mathrm{O}_{2} / \mathrm{C}_{2} \mathrm{H}_{2}$.

\section{References}

1. R. Dhaubhadel, S. C. Gerving, A. Chakrabarti and C. M. Sorensen, Aerosol Sci. Tech., 2007, 41, 804-810. 